\title{
Effects of alkalized cocoa powder and soy lecithin on physical characteristics of chocolate beverage powders
}

\begin{abstract}
Chocolate beverage powders (CBPs) were produced from alkalized cocoa powder (ACP) at $10 \mathrm{ï} 30 \%$ and soy lecithin (SL) at 0ï 4\%. Response surface methodology (RSM) was used to determine the optimum level of ACP and SL on sedimentation, wettability, bulk density, despersibility, moisture content and flavor acceptability. SL was effective on wettability, and it also showed an optimum level for sedimentation and bulk density, while ACP was found to be significant for all physical properties. For sensory evaluation, flavor was acceptable at $20 \%$ ACP level soy taste was detected by panelists in CBPs with high SL and low ACP contents. It was found that as the ACP content was increased the soy taste of CBPs decreased. For overall physical characteristics, the optimum levels of $20 \%$ of ACP and $2 \ddot{1} 4 \%$ of SL were selected.
\end{abstract}

Keyword: Chocolate beverage powders; Alkalized cocoa powder; Soy lecithin; Physical characteristics 